\title{
Food Insecurity Experiences of Idaho Head Start Families
}

\author{
Sherry Deiter, PhD \\ Walden University, Minneapolis, Minnesota, United States \\ iD https://orcid.org/0000-0002-8518-3816 \\ Yitza Arcelay-Rojas, EdD \\ Walden University, Minneapolis, Minnesota, United States \\ (iD) https://orcid.org/o0o0-0002-75.58-3111
}

Contact: sherry.deiter@waldenu.edu

\begin{abstract}
Using the social-ecological model, this basic interpretive qualitative study sought to examine the phenomenon of food insecurity among Idaho Head Start enrolled families, focusing on barriers and deterrents to accessing available nutrition assistance programs. A total of 11 interviews were conducted with parents who had children enrolled in five Idaho Head Start programs. The data were coded and analyzed and are reflective of how individual, interpersonal, community, and organizational levels factors are reflected in participants' decisions to access available nutrition assistance programs. Participants reported feelings of stigma and shame and transportation concerns as individual barriers as well as the interpersonal barrier of a lack of support systems. Lack of awareness of resources, limited food choices, and the questionable quality of foods provided at pantries were noted among the community and organizational deterrents. The results of this study may be used to create interventions that promote food security among Head Start families.
\end{abstract}

Keywords: early childhood; food insecurity; food security; food pantry; food bank; Head Start program; health promotion; nutrition assistance programs; qualitative study; social-ecological model.

Date Submitted: October 28, 2021 | Date Published: January 20, 2021

\section{Recommended Citation}

Deiter, S., \& Arcelay-Rojas, Y. (2021). Food insecurity experiences of Idaho Head Start families. Journal of Social, Behavioral, and Health Sciences, 15, 43-60. https://doi.org/10.5590/JSBHS.2021.15.1.03

\section{Introduction}

Food insecurity, defined as a "household-level economic and social condition of limited or uncertain access to adequate food" (United States Department of Agriculture [USDA], 2020a, para. 6), continues to be a concern for public health (Feeding America, 2020; USDA, 2020b). In 2018, 11 million children faced food insecurity, and it is estimated that one in four or 18 million children in the United States are living in circumstances that threaten food security (Feeding America, 2020). In 2019, 13.6\% of households with children experienced food insecurity (USDA, 2020b). Within the state of Idaho, over 72,00o children face food insecurity daily (The Idaho Foodbank, 2018). Nutrition assistance programs exist to help combat food insecurity, including

Note: We have no conflict of interest to disclose. Correspondence concerning this article should be addressed to Sherry Deiter. Email: sherry.deiter@waldenu.edu 
Supplemental Nutrition Assistance Programs (SNAP), Women Infants \& Children (WIC), food banks, school breakfast program (SBP), national school lunch programs (NSLP), summer food service program (SFSP), and school backpack programs. Participation in programs such as Share Our Strengths Cooking Matters and Eat Smart Idaho has been beneficial for families and positively correlated with adequate food supplies and increased nutrition education skills (Cooking Matters, 2018). Although many families could qualify for numerous nutrition assistance programs, these programs are not being used to their fullest potential (Center on Budget and Policy Priorities, 2020; Cohen et al., 2019; Oliveira, 2017; Trappmann et al., 2015). The most recent report shows that in 2016, nationally, 59\% of food-insecure households were enrolled in federal nutrition assistance programs (Oliveira, 2017), and $84 \%$ of Idahoans who qualify for SNAP were enrolled (Center on Budget and Policy Priorities, 2020). Therefore, barriers may exist that prevent families from using these services (Cohen et al., 2019; Fong et al., 2016).

Households with children and with incomes at or below the federal poverty guidelines continue facing food insecurity at rates higher than the national average (USDA, 2020b). Many families enrolled in Head Start and Early Head Start programs represent those who are at or below federal poverty guidelines, which qualifies them for federal nutrition assistance programs (USDA, 2020c). In the United States, its territories, and tribal communities, the purpose of the Head Start program is to promote "school readiness for children in lowincome families by offering educational, nutritional, health, social, and other services." (Administration for Children \& Families, 2020, p. 1). This program provides balanced snacks and meals to children, but this is not enough to address food insecurity for families (Trappmann et al., 2015). The most recent national data available shows that 33\% of Head Start families face food insecurity (Tarullo et al., 2017). During the 20172018 program year, 5,154 children between the ages of zero and five were served by Head Start and Early Head Start programs across the state of Idaho (Idaho Head Start Association, 2018). In 2017, as stated by the Idaho Head Start Association (n.d.), "87\% of Head Start Children are living below $100 \%$ of the federal level, are homeless, in foster care or on public assistance." Children living under these conditions are more likely to face food insecurity (Trappmann et al., 2015).

Children facing food insecurity have poorer health outcomes and lag behind their peers in academic outcomes, which can lead to a growing disparity among food secure and food insecure children (King, 2018). In addition, food insecurity has been positively associated with child obesity (Cetateanu \& Jones, 2014). Faced with the dilemma of feeding their child, parents might attempt to purchase the largest amount of food they can afford, usually, calorically dense food that is low in nutrients (Cetateanu \& Jones, 2014). Food insecurity also has a negative impact on parents (Harvey, 2016). Being food insecure, along with the associated tradeoffs, can create a cluster of hardships that lead to toxic stress in the home (Chilton et al., 2013; Chilton et al., 2014; Knowles et al., 2015). The negative consequences of food insecurity associated with the adult caregiver include emotional stress, damaged pride, depression, poor mental health status, and a decreased sense of selfworth (Evans et al., 2015; Knowles et al., 2016). These barriers may inhibit parents from accessing available nutrition assistance programs in their communities. Understanding these barriers and deterrents may aid health professionals in the development of interventions that encourage parents of food-insecure families to seek assistance.

To understand the experiences of families facing food insecurity who were enrolled in preselected Idaho Head Start programs, we incorporated the Social-Ecological Model (SEM). The SEM comprises the examination of relationships between individuals and their environments (Glanz et al., 2015). If food insecurity is to be successfully minimized, interpersonal, community, and organizational factors must be identified and addressed along with individual factors that lead a person to being food insecure.

Understanding how individual parental factors, interpersonal family and friend factors, community resources and collaborations, and organizational and social institutions interact with one another may allow researchers to develop interventions that can promote food security. At the individual level, researchers seek to identify 
biological and personal factors that increase the likelihood of being food insecure. Examples of these individual factors include age, education, literacy, financial resources, mental health status, feelings of selfefficacy, and stigma (Sakai \& Umetsu, 2016). These factors are specific to the parent or adult caregiver because young children rely upon an adult to provide them with nourishing food. At the individual level, interventions could focus on promoting families' knowledge, attitudes, beliefs, and behaviors that help to prevent food insecurity. Also, it is important to understand how friends, family, and peers can impact the experience of food insecurity. Increasing social support has been found to have protective factors against food insecurity (King, 2017). At the intrapersonal level, parenting and family-focused interventions are appropriate. At the community level, prevention strategies seek to make a positive impact on social and physical environments. Community factors can influence mental health and impact food security (Uhlmann et al., 2018). Within the organizational level, organizations or social institutions with rules and regulations for operations affect how, or how well, services are provided to individuals and groups (Sakai \& Umetsu, 2016). In this study, the Head Start program, the organizational collaborations, and the structure of food pantries and food banks were the main organizational factors examined based on the participants' perceptions.

Although many studies have focused on food insecurity (Christaldi \& Pazzaglia, 2018; Cook et al., 2013; Frongillo et al., 2016; Garg et al., 2015; Gunderson \& Seligman, 2017), research related to Head Start families living in Idaho is scarce. Also, identification of the factors and barriers that deter Idaho families from accessing these nutrition assistance programs that strive to eliminate childhood hunger appears to be lacking in the research. In order to create interventions that positively address food insecurity, it is essential to gain a better understanding of how the individual, interpersonal, community, and organizational factors may influence Idaho Head Start enrolled families when choosing whether or not to access available nutrition assistance programs. To fill this gap, we examined in this basic qualitative study the experiences of Idaho Head Start families when accessing nutrition assistance programs.

\section{Method}

\section{Participants}

For this basic qualitative study, we collected data within a geographical range, which was narrowed to only include counties in Idaho that have a Head Start program, a population poverty rate of $14 \%$ or higher, a population where at least $50 \%$ of the residents have been determined to be eligible for federal nutrition assistance programs, and a potentiality of food insecurity that impacts at least 1,00o people. We obtained data to meet these criteria from the Map the Meal Gap resource (Feeding America, 2018). Map the Meal Gap is a resource that estimates the rate of food insecurity for both the general population and, separately, children. It is the only resource that reports food insecurity data at the county level (Feeding America, 2018). This resource includes the population of each county in Idaho, food insecurity rates, estimated numbers of food insecure individuals, and percentages of the population that would likely be income eligible for federal nutrition assistance. Using the Map the Meal Gap resource, we found that 11 of the 44 counties in Idaho met the eligibility criteria.

Upon approval from the university's Institutional Review Board (approval number 06-24-19-0523580) Head Start directors of programs that met the inclusion criteria were contacted for written permission to post recruitment flyers. Five of the 11 program directors agreed to display parent recruitment flyers. We concluded recruitment efforts after 11 Idaho Head Start parents were interviewed for this study and data saturation reached. We collected data through individual face-to-face interviews with Idaho Head Start parents who agreed to participate in this study. Participants were parents whose children had just completed enrollment during the 2018-2019 Idaho Head Start program year or were enrolled for the 2019-2020 year. All 11 participants experienced food insecurity in the past or were currently experiencing food insecurity. Ten of the 
11 participants were female, and one participant was male. We obtained demographics regarding age, annual income, ethnicity, and employment status.

\section{Procedures}

The recruitment flyer included the IRB approval number and contained tear-offs with contact information. We emailed informed consent forms to participants and instructed them to read the terms of consent. They returned an email with their electronic signature to confirm their consent to participate in the study. Potential participants had the opportunity to ask any questions they had about the study prior to being interviewed, and appointments for interviews were set up only after participants had reviewed the informed consent and indicated their willingness to be part of the participant pool. Interview reminders were sent via email or text message one day prior to the interview.

The interview guide (see Appendix A for a list of interview questions) aligned and maintained focus on the research questions. The questions had the purpose of gathering insight into the experiences of food insecurity, accessing nutrition assistance programs, and beliefs about purchasing, preparing, and providing healthy foods for families. Face-to-face, semi-structured interviews were conducted at the five Head Start sites where participants had children enrolled. Before beginning each interview, the participants completed the informed consent and granted permission to audio record the interviews. The interviews lasted an average of 90 minutes.

All the audio recorded interviews were transcribed into a Microsoft Word document, returned to participants for review via mail to ensure member checking. Participants received two copies of the interview transcripts by mail once transcription was completed. They signed and returned one copy of the transcript to ensure the transcript was truly reflective of their thoughts, beliefs, and opinions.

\section{Analysis}

We used open codes, categories, and thematic analysis to scrutinize the interview transcripts. Using Dedoose software, we grouped the data into codes. Dedoose is a web-based application software where qualitative data can be imported for coding and analysis (Salmona et al., 2020). Codes were generated with the research questions in mind. We completed coding in two documented cycles and then identified common themes. We categorized the codes into main emergent themes: individual and interpersonal deterrents, individual coping strategies, community factors, and organizational structure deterrents.

Table 1 presents an alignment of the research questions with the emergent themes. The iterative process of coding generated the emergent themes that followed from the data analysis. To facilitate the discussion, we organized these themes into categories aligned with the levels of the SEM. 
Table 1: Emergent Themes Organized Into Categories for Analysis

\begin{tabular}{lll}
\hline \multicolumn{1}{c}{ Research questions } & Emergent themes & Categories \\
\hline $\begin{array}{l}\text { RQ1: How do Idaho Head Start enrolled } \\
\text { families describe personal experiences and } \\
\text { barriers to accessing available nutrition } \\
\text { assistance programs? }\end{array}$ & $\begin{array}{l}\text { Individual deterrents } \\
\text { Coping strategies }\end{array}$ & Individual factors \\
$\begin{array}{l}\text { RQ2: How do Idaho Head Start enrolled } \\
\text { families perceive the interpersonal and } \\
\text { community factors that impact their decision } \\
\text { to access nutrition assistance programs? }\end{array}$ & Interpersonal factors & Community factors \\
$\begin{array}{l}\text { RQ3: How do Idaho Head Start enrolled } \\
\text { families perceive the organizational structure } \\
\text { of entities such as the Idaho Foodbank, } \\
\text { specifically how food distributions are } \\
\text { designed? }\end{array}$ & $\begin{array}{l}\text { Organizational structure } \\
\text { deterrents }\end{array}$ & $\begin{array}{l}\text { Community and } \\
\text { organizational factors }\end{array}$ \\
& & Community and \\
& & \\
\hline
\end{tabular}

\section{Results}

As shown in Table 2, all but one of the participants were female (91\%). Five (45.4\%) of participants were between the ages of 20 and 29, three (27.3\%) were between 30 and 39, and three (27.3\%) were 40 and above. One (9\%) identified as African American, two (18\%) Hispanic, and the other eight (73\%) identified as White. Three (27\%) had an annual income of less than $\$ 9,999$, two (18\%) between $\$ 10,000$ and $\$ 24,999$ and six (55\%) \$25,000 or higher. One (9\%) participant was out of work, two (18\%) were students, three (27\%) homemakers, and five (45\%) were employed full-time. Participants were recruited from five Idaho Head Start programs which are identified as A, B, C, D, or E.

Table 2: Description of Participants' Demographics

\begin{tabular}{lcllll}
\hline Participant & $\begin{array}{c}\text { Head Start } \\
\text { program }\end{array}$ & Age range & \multicolumn{1}{c}{ Income } & Employment & Ethnicity \\
\hline P1 & A & $20-29$ & $\$ 15000-\$ 24999$ & Employed full-time & Hispanic or Latino \\
P2 & A & $30-39$ & $\$ 5000-\$ 9999$ & Student & White \\
P3 & A & $20-29$ & Less than $\$ 5000$ & Student & White \\
P4 & A & $30-39$ & $\$ 25000$ or greater & Employed full-time & African American \\
P5 & B & 40 and above & $\$ 25000$ or greater & Homemaker & Hispanic \\
P6 & C & $20-29$ & $\$ 25000$ or greater & Employed full-time & White \\
P7 & C & $20-29$ & $\$ 25000$ or greater & Employed full-time & White \\
P8 & D & 40 and above & $\$ 25000$ or greater & Homemaker & White \\
P9 & A & $30-39$ & $\$ 15000-\$ 24999$ & Employed full-time & White \\
P10 & E & $20-29$ & $\$ 25000$ or greater & Homemaker & White \\
P11 & E & 40 and above & Less than $\$ 5000$ & Out of work & White \\
\hline
\end{tabular}


The emergent themes were organized into categories aligned with the levels of the SEM. The findings are organized into three main analytic categories: individual factors, interpersonal factors, and community and organizational factors.

\section{Individual Factors}

Participants were asked about individual barriers to accessing nutrition assistance programs. Personal pride, embarrassment, transportation, lack of gasoline money, lack of childcare, and the perceived judgment of others were the main individual deterrents noted regarding accessing nutrition assistance programs. P1 shared, "it hurts my pride to have to ask for help." Similar concerns were expressed by other participants. P3 discussed feelings of judgment and expressed, "people are judging me and thinking I am not a good dad and sometimes, I don't have the car to get to appointments." P7 expressed these concerns as well and she mentioned, "people think I am not a good parent and I can't provide for my kids. That is embarrassing." P9 also expressed a feeling of stigma:

There is a special mark on the SNAP debit card. People see it and they know you use SNAP. People think you can't provide for your kids and they look down on you. It makes you feel inadequate as a parent.

P8 also said, "I have been in arguments with people on Facebook who think I am abusing the system. They think I am using the system, people in the grocery store have lectured me about what is in my cart." These feelings and stigma were described by the participants as emotional barriers to accessing nutrition assistance programs. Additionally, lack of childcare and lack of gas money were mentioned as individual deterrents. P4 shared that she "was expected to try and work during the summer after her kids turned six." She expressed reservations about this when she mentioned, "my son has cystic fibrosis and I did not want to leave him." P6 reported, "I don't always have the gas money to get to appointments. If I can’t find a sitter for my kids, I don't always go to the food bank."

All participants were able to describe coping strategies for shopping in order to get the most out of their money. These strategies included menu planning, making lists, using coupons, shopping sales, shopping weekly or bi-weekly, stocking up, and reusing leftovers. When asked about coping strategies, such as maintaining a private garden and how to best shop on a budget, participants offered several responses. P1 explained, "I live in a small duplex and there is no space for a garden. I have an app on my phone for couponing. I use digital coupons and like the buy five, save five sales."

P2 also shared:

I would love to have my own garden. I had one growing up and am waiting until we can buy a house to start a garden. I shop sales and create meal plans based on what is on sale. We bought a freezer so when meat is on sale, we can stock up. Buying food in season helps. It's not expensive when you buy in season.

P6 explained, "I maintain a tight budget. I plan out menus and only buy these foods along with snacks for the kids.”

P5 shared,

I make a list before I go grocery shopping. If I am running low on money, I buy the most important things on my list. I used to have a garden, but my back is bad, and I can't maintain one.

Nine of the 11 participants expressed that they would like to have their own private garden but lacked the space or the physical ability to maintain a garden. 


\section{Interpersonal Factors}

The main interpersonal deterrents to accessing nutrition assistance programs were the inability or lack of willingness of family, friends, and neighbors to assist with transportation or provision of resources. We asked participants about other support systems they may have, such as family and friends. Two participants reported support systems within their families, friends, and neighbors. These support systems could provide support and assistance. The other nine participants reported a lack of support systems. For example, P1 explained the importance of having supportive family close by, "my parents used to be able to help me take my kids to WIC appointments while I worked, but they moved 20 miles away and can't help. I didn't know about SNAP then." P2 shared, "my husband lost his job mid-shift. The state closed the agency down and we had just moved to a new apartment. There was nobody who could help us." P4 also reported, "I could not ask my family for help. I am the one they go to when they need help." P7, P8, and P11 described similar situations. For instance, P8 noted, "I had a falling out with my sisters after my mom died and we don't speak." P11 shared, "before my husband left, family used to come to me for help with food. It's hard to be on the other side now and so I don't want to ask for help from family and friends."

Other participants explained the importance of support systems, such as neighbors and friends, they can rely on. P3 mentioned, "we used to have great neighbors who we could share food with but, since we moved, our neighbors aren't as friendly.” Similarly, P9 explained, “I cannot rely on family, friends, or neighbors for help with food when I need it." P10 described, "we moved to a small town because we could afford a house there. We have no family living near us and haven't gotten to know the neighbors yet." Overall, most of the participants described how the lack of support systems influenced their food security.

\section{Community and Organizational Factors}

Community resources, or lack thereof, can reduce or promote food insecurity among Idaho Head Start families. In order to understand the community factors that impact the decision to access available nutrition assistance programs, we asked questions about resources available in the community and access to these resources. Parents provided common responses for available nutrition assistance programs, such as WIC, SNAP, food distribution sites, and food boxes. Only two participants reported taking part in the SFSP. Work requirements or lack of transportation limited participation in SFSP by the other participants. Only two participants had even heard of Eat Smart Idaho. Two participants had completed the Cooking Matters program. Other participants had not heard of this resource or were unsure how to take part in the program. All participants noted that facilitators to accessing community nutrition assistance programs were awareness of the resources available to them.

All participants reported community gardens did not exist where they lived, but all parents expressed interest in such a resource if it was well organized and fair to everyone who took part. P2 felt having access to a community garden would be a blessing if it were run correctly. $\mathrm{P}_{5}$ reported having previous experiences with community gardens where she pays $\$ 10$ and can pick the produce she wanted. She would like to see the startup of a new community garden. P7 described the garden at her son's charter school. The garden was popular, and parents were able to take the produce they wanted. P8 discussed the importance placed on community gardens when she was employed with USDA. She felt a community garden would be a great help for communities with a high population of low-income individuals.

Participants were asked to share their knowledge of community resources available to them. P1 responded, "WIC, SNAP, food distribution sites, the Salvation Army, and Eat Smart Idaho are programs available." P9 shared, "WIC is a nutrition assistance program. Oh wait, I guess SNAP is too, but I don't qualify for that." P11 explained, "nutrition assistance programs in my community are food banks, food pantries, and the LDS church." All parents described the support and information they received from their Head Start program as invaluable. Four parents were not familiar with the WIC program prior to enrolling in Head Start. P1O 
reported, "SNAP and WIC are available. I did not know about WIC until my first child started going to Head Start.” The Head Start family advocates assisted these families with the WIC enrollment process. All participants expressed gratitude for the information and support they received from Head Start. For those participants who had older children enrolled in public schools, none reported receiving nutrition assistance information from community resource workers. One participant reported a food pantry being available at an elementary school in their community. Two participants reported their children receiving weekend food backpacks at the end of each school week.

Food distribution sites such as food banks and food pantries provide much-needed food supplies to families who seek out these services. For many families, the foods they receive from food banks and pantries are the difference between going hungry and keeping their children fed. However, the quality of the foods provided at food pantries was worrisome to those who had sought out such services. P10 described her experience, "I got canned foods that were a year and a half past the use-by date. I was afraid it would make my kids sick." Also, concerns about long waits in line with young children were also noted as bothersome, as P6 explained, "the wait times for food boxes are long. Going to the food pantries is not child friendly. One volunteer asked me why I have so many kids.” P1 reported about the food quality as well:

The food was pre-boxed, and I had no choice in what I received. Fruits and vegetables are hard to get, and they aren't always good quality. Sometimes, produce has to be eaten right way and sometimes it has to be thrown out because it is rotten. There is no selection and no substitutions for food allergies. The volunteers are nice and want to help.

Participants described the organizational structure of entities such as the Idaho Food Bank, specifically how food distributions are designed. All participants had accessed services through some type of food pantry and provided insights into the quality of the food that was provided, the food distribution process, and how they were treated by the staff and volunteers. Although they mentioned that the Idaho Food Bank is organized and volunteers are friendly, they shared concerns regarding the food quality.

The food and customer service provided through the Bishop's Storehouse, a food pantry operated by a religious organization, was spoken of positively by those who had sought out their services. The foods were noted to be of high quality and the volunteers were friendly and did not appear to judge those who needed nutrition assistance. $\mathrm{P}_{3}$ described her experience:

The food distribution at the Bishop's Storehouse is organized. Your bishop gives you the list of food and you select what you want. A relief society member walks with you and puts the food in your cart. It is set up like a grocery store. The volunteers are nice and want to help you. It was not a degrading experience.

P4 and P8 had also utilized the Bishop's Storehouse and agreed that they provide good food quality. For instance, $\mathrm{P} 4$ shared, "the food was healthy, and they gave me a cookbook. The food pantries just have rice, bread, and boxed food. The volunteers had smiling faces and were happy to help." P11 was also able to describe experiences with a food pantry and the Bishop's Storehouse. She noted:

At the food pantry, the food was not the greatest. Some of the canned foods were out of date and the fruits and vegetables were moldy. I didn't think the foods were healthy. You have to stand in line for a long time. It's hard to stand in line that long with my health problems and with kids there. The Bishop's Storehouse gives me extra food when they get donations. They are very kind and always ask if I have enough food.

All participants echoed similar sentiments when asked what types of foods they would want to offer if they were managers of a food pantry. All participants would like to see more fresh produce, fresh baked goods, lean 
meats, and dairy products such as yogurt, cheese, and low-fat milk. All participants expressed that they do not prefer boxed meal products, canned meats, and dried out bread products.

\section{Discussion}

Individual influences on health behaviors previously identified include knowledge, beliefs, attitudes, selfefficacy, ethnicity, age, gender, economic status, financial resources, values, goals, literacy, stigma, among others (Sakai \& Umetsu, 2016). The main individual influences that perpetuated food insecurity among participants in this study included a lack of financial resources, perceived stigma from others and the knowledge participants implemented in the form of coping strategies to obtain more food at the grocery store. Regardless of their ethnicity, age, gender, or economic status, these feelings of stigma were common to all participants. For example, P1 expressed feelings of damaged pride when having to ask for help and feared that she would be turned into Child Protective Services as she needed assistance feeding her children. $\mathrm{P}_{3}$ expressed concerns that he is perceived as not being a good dad. $\mathrm{P} 7$ voiced feelings of being judged as a bad parent and not being able to provide for her children. This was embarrassing for her. These emotions and feelings concur with the study of Middleton and colleagues (2018) who also found that feelings of humiliation, guilt, and powerlessness among respondents, along with a sense of perceived judgment, represent individual factors that could constitute a barrier to improved food security. This perceived stigma may inhibit those in need of nutrition assistance from seeking out services, which supports continued food insecurity.

A second individual factor noted by parents in this study was lack of financial resources, primarily a lack of gas money or transportation to get to nutrition assistance programs. For instance, P1 relied on her parents for transportation to appointments before they moved to another town. $\mathrm{P}_{3}$ reported he did not always have a car to get to appointments while P6 did not always have the gas money to get to appointments. A lack of transportation among those in need of nutrition assistance services could reinforce food insecurity (Wiig Dammann \& Smith, 2009).

A third individual factor discussed by participants is knowledge and coping strategies to save money. Possessing the knowledge to employ coping strategies that positively address food insecurity can increase a sense of self-efficacy among those who experience food insecurity (Burke et al., 2018; Matwiejckz et al., 2018). Participants described couponing strategies to save money at the grocery store, shopping sales and creating meal plans based on what was on sale, and purchasing a freezer in order to stock up on meats when they were on sale. Other participants created a list before they went shopping and bought only the most important items on the list when starting to run low on money. One participant described maintaining a tight food budget and creating menus, purchasing only the items she needed for her menus along with snacks for kids. Employing coping tools increased self-efficacy among participants and aided them in purchasing more food with the financial resources available to them.

Formal and informal social networks as well as social support systems are a part of the interpersonal level of the SEM and can influence individual health behaviors. These networks can include family, friends, coworkers, and religious networks (Sakai \& Umetsu, 2016). The main interpersonal factors noted in this research study were lack of support and a lack of networks between family and friends. Only two of the 11 participants in this study reported having supports they could rely on in times of need. Additionally, P4, P8, and P9 responded they could not ask family for help. P10 and her family had just moved to a new town in order to purchase an affordable home and had not formed relationships with her new neighbors. These findings are congruent with the recommendations of creating a strong social safety net and social networks among extended family in order to care for the nutritional needs of children and reduce the risk of material hardship (DeLorme et al., 2017; King, 2016;). Such social supports and networks can provide assistance when needs arise and would be beneficial for all who face food insecurity. 
A support system helped those facing food insecurity develop a sense of belonging. For example, P10 identified the importance of peer support. She shared that the connections and support she forged with other Head Start parents were helpful. She reported that others in need of help have a better understanding of the struggles she faces, and it helped her feel like she is not an outcast. These findings are congruent with the Fiese et al. study (2016), which found that participation in nutrition assistance programs that incorporated education activities on how to stretch food dollars also helped participants connect with other peers. Also, support systems are necessary to help those in need find the resources they need. Participants in this research reported hearing about programs such as WIC and SNAP from family, friends, or the Head Start family advocate. P1 heard about WIC and SNAP from friends while P2 heard about WIC from her sisters. P7 heard about WIC from her Head Start family advocate. Therefore, similar to what other studies have found, it is important to advocate for support systems that focus on getting eligible families enrolled in nutrition assistance programs (Miller et al., 2014).

Relationships among organizations, institutions, and informational networks within defined boundaries can impact health choices, as noted within the community level of the SEM. Collaborations, community leaders, businesses, and transportation options may influence health (Sakai \& Umetsu, 2016). The main community factors promoting food insecurity that were noted in this study included a lack of community supports, a need for improved informational networks, and a lack of community collaborations. A community support that could be an asset for those facing food insecurity are community gardens (Uhlmann et al., 2018). All participants reported community gardens did not exist where they lived, but all parents expressed interest in such a resource if it was well organized and fair to everyone who took part. When participants in this research study were asked about supports such as community gardens, none reported access to such a resource. These findings resonate with previous research which advocated for the creation of community and school gardens to help alleviate food insecurity (Uhlmann et al., 2018).

A second community factor noted in this research that perpetuated food insecurity is related to informational networks. Participants identified a lack of awareness of available resources and a lack of awareness of who to ask about available resources. Three parents in this research study noted that being aware of the resources available in their communities made it easier to participate in nutrition assistance programs. Increased awareness of available resources can positively address food insecurity. In 2015, the American Academy of Pediatrics (AAP) recommended that medical schools incorporate curriculum that educated medical students about community resources, specifically those that promoted food security. Additionally, Head Start family advocates share information with families regarding community resources. The sharing of information about available resources in multiple environments helps increase awareness. It appears that increased marketing of available programs is necessary to promote awareness among the target population.

Within the organizational level of the SEM, organizations or social institutions with rules and regulations for operations affect how, or how well, services are provided to individuals and groups (Sakai \& Umetsu, 2016). In this research, the Head Start program, the lack of organizational collaborations between Head Start and WIC programs, technological needs, and the structure of food pantries and food banks were the main organizational factors identified by participants. The creations of coalitions and partnerships would help increase awareness of all community programs that are available (Ke \& Fords Jones, 2015).

The mission of Head Start programs is to "promote the school readiness of young children from low-income families by enhancing their cognitive, social, and emotional development" (Administration for Children \& Families, 2020, p. 1). All participants in this research study expressed gratitude for the information and assistance they obtained from Head Start staff regarding available nutrition assistance programs. Participants described Head Start staff as "awesome." P4 described how Head Start staff would help parents in need get to appointments by providing transportation. P6 described her family advocate as "amazing" and told her about 
a community food pantry at a local school. All participants in this study described benefitting from the services they received from the Head Start programs their children were enrolled in.

None of the 11 participants in this research study were involved in Head Start programs where a collaboration was in place with WIC to provide on-site services at their Head Start centers. Collaborations between WIC programs and Head Start programs were advocated for in other research studies (Martin et al., 2014). Such collaborations can promote enrollment in organizations that positively address food insecurity. Creating reciprocal collaborations where information about available resources can be provided would be beneficial to the individual organizations as well.

Another organizational factor noted in this study was technological needs in the form of reminders for appointments. P2 reported that she sometimes forgot her WIC appointments but is now receiving text message reminders. This aligns with previous research that advocated for WIC programs to start sending out text message reminders for appointments (Whaley et al., 2017). Courtesy reminders for appointments are not only beneficial for WIC recipients, but also WIC agencies. The amount of funding dollars received by WIC agencies is contingent on the number of participants they serve (USDA, 2020d).

A third organizational factor is the organizational structure of food pantries and food banks. Parents in this research described food pantries as lacking individual choice, as food boxes were all stocked with the same foods. Participants reported that they did not get to select the foods they wanted as it was all pre-boxed. In addition to the lack of choice, participants in this research also noted dissatisfaction with the quality of the foods received at food pantries. They voiced concerns that the food looked old and not healthy. They mentioned that meat appeared to be thawed and refrozen, and fruits and vegetables were noted to be rotten or close to rotten. P10 voiced concerns that the canned foods were often expired and received canned goods that were a year and a half past the use-by date. Respondents in other research studies also noted dissatisfaction with the quality of the foods received (Middleton et al., 2018). Foods provided that are not edible do nothing to positively address food insecurity.

Those participants who had accessed the Bishop's Storehouse described a very different experience than those who had visited a food pantry. The Bishop's Storehouse is a food pantry operated by a religious organization throughout Idaho. Participants described this food pantry as being set up similar to a grocery store where the church bishop provides them with a list of items available and they choose what they want. They also noted that the Bishop's Storehouse provided quality ingredients to prepare fresh meals. They explained that a volunteer accompanies them through the storehouse and helps them choose the foods they need. Setting up food pantries like grocery stores was determined to be more effective in reducing food insecurity (Middleton et al., 2018). Participants in other food insecurity studies noted less food insecurity when they could choose the foods that were desired in their homes (Middleton et al., 2018). Likewise, participants in this study noted that when they received foods of their personal choice, it helped to alleviate food insecurity in their homes.

\section{Recommendations}

This study identified barriers and deterrents to accessing available nutrition assistance programs relative to families enrolled in Idaho Head Start programs. These identified barriers include feelings of stigma and fear, transportation barriers, lack of support systems, lack of awareness of available community programs, concerns with the quality of foods received from food banks, dissatisfaction with customer service, and difficulty using resources at grocery stores. All participants shared experiences of facing food insecurity. They also shared experiences, both positive and negative, when reaching out to agencies that are in place to alleviate food insecurity. 
The data generated from this study illustrated that multiple issues interplay with one another to promote food insecurity and multiple levels of intervention are necessary. For instance, at the individual level, many participants noted transportation barriers. At the interpersonal level, many participants reported not having a support system. Creating an office where food-insecure families can access multiple services would help alleviate this deterrent. The Family Center, located in Findlay, Ohio, offers a wide array of services for lowincome families. This center houses services for low-income families that include clothing, food, dental, medical, legal, financial, housing, immunizations, transportation, medical prescriptions, and utility assistance (The Family Center, 2019). Such an entity would positively address individual and interpersonal barriers. Families could trade off on childcare and transportation with one another, thereby creating support for one another. Such an entity may diminish concerns of judgment and fear of repercussions as local citizens work together to meet community needs.

Overall, it is equally important to educate families and also professionals who can also promote food security. Nutrition education interventions can be aimed at improving skills enhancements for families and institution members beyond target the population, including community leaders and health professionals. It is essential for health professionals to familiarize themselves with community resources that address food insecurity through nutrition assistance services (AAP, 2015). At the community level, we also advocate for the creation of partnerships and coalitions that would help community agencies support one another and spread the word of resources that are available to those in need. For example, Eat Smart Idaho is a community program that provides education on topics such as healthy eating, smart shopping, food safety, quick meal preparation, management of limited grocery dollars, and increasing physical activity (Eat Smart Idaho, 2018). Providing information on this program at food pantries and other assistance provision entities would help increase visibility for Eat Smart Idaho. At the organizational level, creating partnerships between WIC and Head Start programs would be an excellent way to coordinate services. WIC staff could set up at Head Start centers once a month and provide services to parents as they drop off their children for class. Such a partnership has been supported by previous research as it was found to be beneficial for Head Start families in Vermont and South Dakota (Martin et al., 2014).

Potential positive social change implications from this study include assisting health researchers in understanding and addressing barriers that negatively impact access to available nutrition assistance programs and identifying community programs that address food insecurity. The findings can be used to help health professionals create interventions to address identified factors that deter research participants from accessing available nutrition assistance programs. These potential interventions may aid Idaho Head Start enrolled families with gaining access to high-quality and increased quantity of foods. With regular access to high-quality and increased quantity of foods, children may experience fewer illnesses, decreased social isolation and depression, lower incidence of obesity, and have better opportunities to achieve academically (Althoff et al., 2016; Gunderson \& Seligman, 2017). Decreasing the incidence of food insecurity can improve physical and mental health. Improving the quality of life of food insecure children promotes positive social change. The communities they reside in and schools they attend are strengthened as children are provided with better opportunities to succeed in life (Carlson \& Keith-Jennings, 2018).

\section{Limitations of the Study}

It is also important to emphasize that the results of this study can only describe the experiences of participants and cannot be generalized to the greater population of Head Start parents. Additional research is necessary in order to gain deeper understanding of how to positively address food insecurity. Endeavors in future research should focus on how to encourage participation in programs that positively address food insecurity. More research is required to determine the correlation between participating in classes such as Cooking Matters and Eat Smart Idaho and reducing food insecurity among participants. It is also important to explore how parents of food insecure children will continue to struggle with feelings of inadequacy as a 
provider, guilt, and anger with themselves and their situation. This study took place before the COVID-19 pandemic; therefore, additional qualitative studies could shed light on the thoughts and feelings of children and their parents who are experiencing food insecurity, particularly during the pandemic. This type of research can aid public health professionals in developing interventions that promote food security. 


\section{References}

Administration for Children \& Families. (2020). Office of Head Start. https://eclkc.ohs.acf.hhs.gov/sites/default/files/pdf/no-search/hs-program-fact-sheet-2019.pdf

Althoff, R., Ametti, M., \& Bertmann, F. (2016). The role of food insecurity in developmental psychopathology. Preventive Medicine, 92, 106-109. https://doi.org/10.1016/j.ypmed.2016.08.012

American Academy of Pediatrics. (2015). Promoting food security for all children. https://pediatrics.aappublications.org/content/pediatrics/early/2015/10/20/peds.2015-3301.full.pdf

Burke, M., Martini, L., Blake, C., Younginer, N., Draper, C., Bell, B., Liese, A., \& Jones, S. (2018). Stretching food and being creative: Caregiver responses to child food insecurity. Journal of Nutrition Education Behavior, 49(4), 296-303. https://doi.org/10.1016/j.jneb.2016.11.010

Carlson, S., \& Keith-Jennings, B. (2018). SNAP is linked with improved nutritional outcomes and lower health care costs. https://www.cbpp.org/sites/default/files/atoms/files/1-17-18fa.pdf

Center on Budget and Policy Priorities. (2020). Idaho food stamp program. https://www.cbpp.org/sites/default/files/atoms/files/snap factsheet idaho.pdf

Cetateanu, A., \& Jones, A. (2014). Understanding the relationship between food environments, deprivation and childhood overweight and obesity: Evidence from a cross sectional England-wide study. Health \& Place, 27(100), 68-76. https://doi.org/10.1016/j.healthplace.2014.01.007

Chilton, M., Knowles, M., Rabinowich, J., \& Arnold, K. (2014). The relationship between childhood adversity and food insecurity: "It's like a bird nesting in your head." Public Health Nutrition, 18(14), 26432653. https://doi.org/10.1017/S1368980014003036

Chilton, M., Rabinowich, J., \& Woolf, N. (2013). Very low food security in the USA is linked with exposure to violence. Public Health Nutrition, 17(1), 73-82. https://doi.org/10.1017/s1368980013000281

Christaldi, J., \& Pazzaglia, G. (2018). An exploration of the influences contributing to food insecurity in Chester County, Pennsylvania. Health Promotion Practice. https://doi.org/10.1177/1524839918801588

Cohen, A. J., Oatmen, K. E., Heisler, M., Hesterman, O. B., Murphy, E. C., Zick, S. M., \& Richardson, C. R. (2019). Facilitators and barriers to supplemental nutrition assistance program incentive use: Findings from a clinic intervention for low-income patients. American Journal of Preventive Medicine, 56(4), 571-579. https://doi.org/10.1016/j.amepre.2018.11.010

Cook, J. T., Black, M., Chilton, M., Cutts, D., Ettinger de Cuba, S., Heeren, T. C., Rose-Jacobs, R., Sandel, M., Casey, P. H., Coleman, S., Weiss, I., \& Frank, D. A. (2013). Are food insecurity's health impacts underestimated in the U.S. population? Marginal food security also predicts adverse health outcomes in young U.S. children and mothers. Advances in Nutrition, 4(1), 51-61. https://doi.org/10.3945/an.112.003228

Cooking Matters. (2018). What we do. https://cookingmatters.org/what-we-do

DeLorme, A., Gavenus, E., Salmen, C., Benard, G. O., Mattah, B., Bukusi, E., \& Fiorella, K. (2017). Nourishing networks: A social-ecological analysis of a network intervention for improving household nutrition in Western Kenya. Social Science \& Medicine, 197, 95-103. https://doi.org/10.1016/j.socscimed.2017.11.023

Eat Smart Idaho. (2018). https://www.uidaho.edu/extension/eat-smart-idaho/about 
Evans, A., Banks, K., Jennings, R., Nehme, E., Nemec, C., Sharma, S., Hussaini, A., \& Yaroch, A. (2015). Increasing access to healthful foods: A qualitative study with residents of low-income communities. International Journal of Behavioral Nutrition and Physical Activity, 12 (Suppl 1). https://doi.org/10.1186/1479-5868-12-s1-s5

Feeding America. (2018). Map the meal gap 2018: Overall food insecurity in Idaho by county in 2016. https://idahofoodbank.org/wp-content/uploads/2018/05/ID AllCountiesMMG 2016 Final.pdf

Feeding America. (2020). Child hunger in America. https://www.feedingamerica.org/hunger-in-america

Fiese, B., Gunderson, C., Koester, B., \& Jones, B. (2016). Family chaos and lack of mealtime planning is associated with food insecurity in low income households. Economics and Human Biology, 21, 147155. https://doi.org/10.1016/j.ehb.2016.01.004

Fong, K., Wright, R., \& Wimer, C. (2016). The cost of free assistance: Why low-income individuals do not access food pantries. The Journal of Sociology \& Social Welfare, 43(1), 71-93. https://scholarworks.wmich.edu/jssw/vol43/iss1/6

Frongillo, E., Bernal, J., Adams, E., Massey, E., Rosemond, T., \& Blake, C. (2016). Altered daily activities and shame resulting from children experiencing food insecurity in rural South Carolina and Oregon. The Federation of American Societies for Experimental Biology (FASEB Journal), 30(1). https://faseb.onlinelibrary.wiley.com/doi/abs/10.1096/fasebj.30.1 supplement.149.3

Garg, A., Toy, S., Tripodis, Y., Cook, J., \& Cordella, N. (2015). Influence of maternal depression on household food insecurity for low-income families. Academic Pediatrics, 15(3), 305-310. https://doi.org/10.1016/j.acap.2014.10.002

Glanz, K., Rimer, B., \& Viswanath, K. (2015). Health behavior: Theory, research, and practice. (5th ed.). Jossey-Bass.

Gundersen, C., \& Seligman, H. K. (2017). Food insecurity and health outcomes. The Economist's Voice, 14(1).

Harvey, K. (2016). "When I go to bed hungry and sleep, I'm not hungry": Children and parents' experiences of food insecurity. Appetite, 99(1), 235-244. https://doi.org/10.1016/jappet.2016.01.004

Idaho Head Start Association. (2018). Annual report program year 2016-2017. https://static1.squarespace.com/static/56a6964e5827c30dgeoa278b/t/5a655104ec212d8a1b9a667a/ 1516589318483/IHSA+-+2017+Annual+Report.pdf

Idaho Head Start Association. (n.d.). Fact sheets. https://www.idahohsa.org/fact-sheets

Ke, J., \& Ford-Jones, E. (2015). Food insecurity and hunger: A review of the effects on children's health and behavior. Pediatrics \& Child Health, 2O(2), 89-91. https://doi.org/10.1093/pch/pxx086.046

King, C. (2016). Food insecurity and housing instability in vulnerable families. Review of Economics of the Household. https://doi.org/10.1007/s11150-016-9335-Z

King, C. (2017). Informal assistance to urban families and the risk of household food insecurity. Social Science \& Medicine, 189, 105-113. https://doi.org/10.1016/j.socscimed.2017.07.030

King, C. (2018). Food insecurity and child behavior problems in fragile families. Economics \& Human Biology, 28, 14-22. https://doi.org/10.1016/j.ehb.2017.11.002

Knowles, M., Rabinowich, J., Ettinger de Cuba, S., Becker Cutts, D., \& Chilton, M. (2016). "Do you wanna breathe or eat?” Parent perspectives on child health consequences of food insecurity, trade-offs, and toxic stress. Maternal and Child Health Journal, 20, 25-32. https://doi.org/10.1007/s10995-015$\underline{1797-8}$ 
Martin, K., Wolff, M., Lonczak, M., Chambers, M., \& Cooke, C. (2014). Formative research to examine collaboration between special supplemental nutrition program for women, infants, and children and Head Start programs. Journal of Maternal and Child Health, 18, 326-332. https://doi.org/10.1007/s10995-013-1237-6

Matwiejczyk, L., Mehta, K., Scott, J., Tonkin, E., \& Coveney, J. (2018). Characteristics of effective interventions promoting healthy eating for preschoolers in childcare settings: An umbrella review. Nutrients, 1O(3), 293-314. https://doi.org/10.3390/nu10030293

Middleton, G., Mehta, K., McNaughton, D., \& Booth, S. (2018). The experiences and perceptions of food banks amongst users in high-income countries: An international scoping review. Appetite, 120(1), 698-708. https://doi.org/10.1016/j.appet.2017.10.029

Miller, D., Nepomnyaschy, L., Ibarra, G. L., \& Garasky, S. (2014). Family structure and child food insecurity. American Journal of Public Health, 104(7), 70-77. https://doi.org/10.2105/ajph.2014.302000

Oliveira, V. (2017). The food assistance landscape: FY 2016 annual report, EIB-169. https://www.ers.usda.gov/webdocs/publications/82994/eib-169.pdf?v=8123.9

Sakai, S., \& Umetsu, C. (2016). Social-ecological models in transition. Springer.

Salmona, M., Lieber, E., \& Kaczynski, D. (2020). Qualitative and mixed methods data analysis using Dedoose: A practical approach for research across the social sciences. SAGE publications, Inc.

Tarullo, L., Knas, E., Kopack Klein, A., Aikens, N., Malone, L.,\& Harding, J. F. (2017). A National Portrait of Head Start Children and Families: FACES 2014. OPRE Report 2017-98. Washington, DC: Office of Planning, Research, and Evaluation, Administration for Children and Families. https://files.eric.ed.gov/fulltext/ED583613.pdf

The Family Center. (2019). About us. https://www.hancockfamilycenter.org/about/about

The Idaho Foodbank. (2018). Media. https://www.idahofoodbank.org/media/

Trappmann, J. L., Jimenez, E. Y., Keane, P. C., Cohen, D. A., \& Davis, S. M. (2015). Cross-sectional relationships between household food insecurity and child BMI, feeding behaviors, and public assistance utilization among Head Start children from predominantly Hispanic and American Indian communities in the study. Journal of Hunger \& Environmental Nutrition, 10(4), 439-455. https://doi.org/10.1080/19320248.2014.962770

Uhlmann, K., Lin, B., \& Ross, H. (2018). Who cares? The importance of emotional connections with nature to ensure food security and wellbeing in cities. Sustainability, 1O(6), 169-176. https://doi.org/10.3390/su10061844

United States Department of Agriculture. (2020a). Definitions of food insecurity. https://www.ers.usda.gov/topics/food-nutrition-assistance/food-security-in-the-us/definitions-offood-security.aspx

United States Department of Agriculture. (2020b). Food security in the U.S. https://www.ers.usda.gov/topics/food-nutrition-assistance/food-security-in-the-us/key-statisticsgraphics/

United States Department of Agriculture. (2020c). Supplemental nutrition assistance program (SNAP). https://www.fns.usda.gov/snap/supplemental-nutrition-assistance-program

United States Department of Agriculture. (2020d). Women, infants, and children program (WIC). https://www.fns.usda.gov/wic 
Whaley, S., Whaley, M., Au, L., Gurzo, K., \& Ritchie, L. (2017). Breastfeeding is associated with higher retention in WIC after age 1. Journal of Nutrition Education and Behavior, 49(10), 810-816. https://doi.org/10.1016/j.jneb.2017.07.003

Wiig Dammann, K., \& Smith C. (2009). Factors affecting low-income women's food choices and the perceived impact of dietary intake and socioeconomic status on their health and weight. Journal of Nutrition Education and Behavior, 41(4), 242-253. https://doi.org/10.1016/j.jneb.2008.07.003 


\section{Appendix A: Interview Questions}

A. How would you define healthy food/meals?

B. Are the healthy foods you want affordable?

C. Do you have stores in your area that carry healthy foods?

D. Do you feel like the stores in your area carry the healthy foods you want?

E. Please share your thoughts and beliefs about how to best shop for foods on a budget.

F. Do you feel you can prepare healthy meals in your home?

G. Do you have the tools you need to prepare healthy meals in your home? Please include availability of cooking tools, such as ovens, pot/pans, microwave ovens.

H. How do you think children are affected when they can't eat a healthy diet?

I. What nutrition assistance services are available in your community?

J. Beside nutrition assistance services, are there other ways you can get food? Can you rely on family, friends, neighbors for help with getting food when needed?

K. Please share your thoughts and experiences about having your own private garden.

L. Please share your thoughts about participating in a community garden.

M. How would you describe your interactions with school community resource workers who can refer you to school related nutrition assistance programs?

N. Can you tell me about a time when it was difficult for you to get the food you needed?

0. Do you ever feel like you do not have the kinds of food in your home that you would like to have?

P. Can you describe deterrents and barriers as you see them personally when choosing to not use an available nutrition service?

Q. Can you describe facilitators as you see them personally when choosing to use an available nutrition service?

R. What things make it easier to access nutrition assistance programs?

S. What things make it harder to access nutrition assistance programs?

T. If you have accessed a food bank or pantry, how would you describe the food items provided to you? Do you feel the food was healthy? Was the kinds of food available the kind of food you usually make for yourself and your family?

U. If you have accessed a food bank, how would you describe the way food was distributed?

V. If you were the manager of a food pantry, what foods would you want available?

W. Do you think there is a stigma around using a food bank? How so?

$\mathrm{X}$. How do you feel about the customer service of staff and volunteers at food banks/pantries?

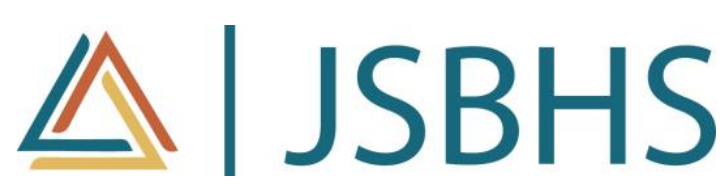

The Journal of Social, Behavioral, and Health Sciences (JSBHS), co-sponsored by the College of Health Sciences and the College of Social and Behavioral Sciences at Walden University, is a peer-reviewed, online, interdisciplinary journal focusing on theoretically-based research that addresses contemporary national and international issues. JSBHS articles include peer-reviewed research reports, brief reports, comprehensive literature reviews, books reviews, and student research. 